\title{
The Impact of Fibromyalgia on Daily Women: A Contribution to Nursing Assistants
}

\author{
Gabriela Carneiro ${ }^{1}$, Ana Paola Geronassoํㅜ, Maria Elisa Brum do Nascimento ${ }^{1}$, \\ Luiz Claudio Sobrinho do Nascimento ${ }^{1}$, Denise Faucz Kletemberg', \\ Giovanna Batista Leite Veloso ${ }^{1}$, Ricardo C. Cunha' ${ }^{1}$, Luiz Cesar Guarita-Souza ${ }^{2}$, \\ Rossana B. Simeoni ${ }^{2,3}$, Julio C. Francisco' ${ }^{1}$, Kátia Renata Antunes Kochla ${ }^{1}$ \\ ${ }^{1}$ School of Nursing \& Health Studies, Positivo University, Curitiba, Brazil; ${ }^{2}$ School of Medical Sciences, Pontifical \\ Catholic University of Paraná, Curitiba, Brazil; ${ }^{3}$ The Paraná Institute of Technology, Curitiba, Brazil
}

Correspondence to: Julio C. Francisco, julio.apfr@gmail.com

Keywords: Fibromyalgia, Depression, Nursing, Pain, Quality of Life

Received: January 30, $2019 \quad$ Accepted: March 9, $2019 \quad$ Published: March 12, 2019

Copyright $\odot 2019$ by authors and Scientific Research Publishing Inc.

This work is licensed under the Creative Commons Attribution International License (CC BY 4.0).

http://creativecommons.org/licenses/by/4.0/

\section{(c) () Open Access}

\section{ABSTRACT}

Objective: To evaluate the impact of fibromyalgia in daily and associated factors in women treated at the polyclinic in Paraná. Method: A descriptive, cross-sectional study was conducted with individualized data for 52 women $\geq 50$ years from the policlinic of the Curitiba of Paraná State, Brazil. Data were collected an online survey and the quality of life was assessed by one specific instrument, the Fibromyalgia Impact Questionnaire (FIQ). Verbal or written informed consent was obtained from all participants. Results: A total of 157 patients completed the survey. The average age was approximately 50 years (range $29-77$ years). The most frequent comorbidities were depression (61.5\%) and (19\%) arthrosis. Conclusion: The understanding of the commodities associated with fibromyalgia helps health professionals to reach the patient efficiently in their orientations about nursing care in women with fibromyalgia.

\section{INTRODUCTION}

The quality of life has impacted in daily on women with fibromyalgia (FM). Globally maintaining these women with health and quality of life is a challenge with the increasing numbers [1]. They also face chronic diseases in all areas of the body, including a decrease in skeletal muscular function, joint pain, general exhaustion and chronic fatigue [2].

Data for an increasing FM prevalence in adults showed $0.2 \%$ and $6.6 \%$ of the general population, with a ratio of approximately $2.4 \%$ and $6.8 \%$ in women [3]. In Brazil, the prevalence was estimated to $5.5 \%$ of over 65-year-old population in São Paulo city [4]. 
This disease affects the patients and all his family. Patients have a reduction in sleep, of the physical functions, anxiety, depression, leading to decreased social interaction and productivity. Treatments of fibromyalgia remain unclear, involving pharmacological and non-pharmacological treatments that have limited efficacy [5]. The disadvantages are that other authors associated with the symptoms of depression, with or without a diagnosis of depressive disorder, assigning functional loss caused by other serious health problems [6] [7].

In this context, nurses provide a crucial contribution, albeit by moments, from the personal world, including the provision of psychosocial interventions and a humanistic look towards the patient with fibromyalgia [8]. Thus, nursing's commitment to mitigate discomforts goes beyond physical and biological interventions.

The aim of this study was to evaluate the impact of fibromyalgia in daily and associated factors in women treated at the polyclinic in Paraná.

\section{METHODS}

In this descriptive, transversal study, data were obtained by sociodemographic and clinical variables. The quality of life was assessed by a specific instrument, the Fibromyalgia Impact Questionnaire (FIQ). An online survey was sent to several women in treatment at polyclinic in the city of Curitiba, Paraná, Brazil. Verbal or written informed consent was obtained from each participant $(n=157)$ before the initiation of the study. Ethics were reviewed and approved by the Ethics Committee of Positivo University.

\section{Data Analysis}

Statistical analyzes were performed using the software (Prism 6.0, Graph Pad Software Inc., La Jolla, Calif). We used descriptive statistics to summarize data demographics, and Common clinical presentation of fibromyalgia. The data were expressed in numbers and percentage.

\section{RESULTS}

A total of 157 women in treatment (52 women) completed the survey. The average age was approximately 50 years (range 29 - 77 years) (Table 1 ).

Depression (61.5\%) and arthrosis (19\%) were the most commonly reported by women, followed by hypertension problems, hypothyroidism, bursitis and diabetes (Table 2).

\section{DISCUSSION}

The results of this study, depression, and arthrosis ranked first and hypertension ranked second among the problems reported by the women (Table 2).

The depression process has been considered the most important risk factor for decreased productivity in people with fibromyalgia [9]. Previous studies also suggested that depression is among the decreasing of cognitive dysfunction and social interaction [10].

Table 1. Demographic characteristics of the women with fibromyalgia.

\begin{tabular}{|c|c|c|}
\hline VARIABLE & PARTICIPANTS & $\%$ \\
\hline Age, mean (SD) & $50 \pm 27$ & \\
\hline Range & $29-77$ & \\
\hline \multicolumn{3}{|l|}{ Profession, $\mathrm{n}(\%)$} \\
\hline Retiree & $8(15.38)$ & \\
\hline Housewife & $11(21.15)$ & \\
\hline Others & $33(63.46)$ & \\
\hline
\end{tabular}


Table 2. Common clinical presentation of fibromyalgia.

\begin{tabular}{ccc}
\hline VARIABLE & NUMBERS & $\%$ \\
\hline Depression & $32(61.54)$ & \\
Arthrosis & $10(19.33)$ & \\
Hypertension & $8(15.38)$ & \\
Others & $2(3.85)$ & \\
\hline
\end{tabular}

Overall, our findings thus indicate that FM patients with a combination of depression, diffuse joint pain and other comorbidity interfere in daily activities and labor productivity.

The present study found that the percentage of depression was higher among the participants (59.61\%) with a mean age of 50 years. The analysis of the individual performances revealed that the lack of support generates poor execution in the daily work capacity in almost half of the patients with FM.

However, previous studies showing impairment on performance in FM patients $[9,11]$.

Carta et al. in 2018 [12] explained that association of the depression, bipolar disorders, and other comorbidity decreases the quality of life and productivity of patients with FM.

Given the lack of research in clinical care for patients with fibromyalgia and we feel that the dissemination of our clinical experience can help nursing care for patients with this disease. From this context, the health team needs to know and establish interventions to mitigate and provide quality of life of these women, because the limitations caused by pain and other symptoms impose an exhausting routine.

\section{CONCLUSION}

Fibromyalgia disorders persons have some limitation; therefore, they require nurse support to optimize daily work. Our results suggest that depression is associated with a decrease in the quality of life of these women's daily lives. The understanding of the commodities associated with fibromyalgia helps health professionals to reach the patient efficiently in their orientations about nursing care in women with fibromyalgia.

\section{ACKNOWLEDGEMENTS}

The financial support was made by CNPq (National Research Council).

\section{CONFLICTS OF INTEREST}

None declared.

\section{REFERENCES}

1. Salaffi, F., Di Carlo, M., Carotti, M., Farah, S., Ciapetti, A. and Gutierrez, M. (2019) The Impact of Different Rheumatic Diseases on Health-Related Quality of Life: A Comparison with a Selected Sample of Healthy Individuals Using SF-36 Questionnaire, EQ-5D and SF-6D Utility Values. Acta Biomed, 89, 541-557.

2. Bennett, R.M. (2009) Clinical Manifestations and Diagnosis of Fibromyalgia. Rheumatic Disease Clinics of North America, 35, 215-232. https://doi.org/10.1016/j.rdc.2009.05.009

3. Grayston, R., Czanner, G., Elhadd, K., Goebel, A., Frank, B., Uceyler, N., Malik, R.A. and Alam, U. (2018) A Systematic Review and Meta-Analysis of the Prevalence of Small Fiber Pathology in Fibromyalgia: Implications for a New Paradigm in Fibromyalgia Etiopathogenesis. Seminars in Arthritis and Rheumatism, In Press. https://doi.org/10.1016/j.semarthrit.2018.08.003

4. Santos, A.M., Burti, J.S., Lopes, J.B., Scazufca, M., Marques, A.P. and Pereira, R.M. (2010) Prevalence of Fibro- 
myalgia and Chronic Widespread Pain in Community-Dwelling Elderly Subjects Living in Sao Paulo, Brazil. Maturitas, 67, 251-255. https://doi.org/10.1016/j.maturitas.2010.07.006

5. Angel Garcia, D., Martinez Nicolas, I. and Saturno Hernandez, P.J. (2016) Clinical Approach to Fibromyalgia: Synthesis of Evidence-Based Recommendations, a Systematic Review. Reumatologia Clinica, 12, 65-71.

6. Borg, C., Padovan, C., Thomas-Anterion, C., Chanial, C., Sanchez, A., Godot, M., Peyron, R., De Parisot, O. and Laurent, B. (2014) Pain-Related Mood Influences Pain Perception Differently in Fibromyalgia and Multiple Sclerosis. Journal of Pain Research, 7, 81-87. https://doi.org/10.2147/JPR.S49236

7. Ojeda, B., Duenas, M., Salazar, A., Mico, J.A., Torres, L.M. and Failde, I. (2018) Factors Influencing Cognitive Impairment in Neuropathic and Musculoskeletal Pain and Fibromyalgia. Pain Medicine, 19, 499-510. https://doi.org/10.1093/pm/pnx024

8. Egeli, N.A., Crooks, V.A., Matheson, D., Ursa, M. and Marchant, E. (2008) Patients' Views: Improving Care for People with Fibromyalgia. Journal of Clinical Nursing, 17, 362-369. https://doi.org/10.1111/j.1365-2702.2008.02505.x

9. Pidal-Miranda, M., Gonzalez-Villar, A.J., Carrillo-de-la-Pena, M.T., Andrade, E. and Rodriguez-Salgado, D. (2018) Broad Cognitive Complaints but Subtle Objective Working Memory Impairment in Fibromyalgia Patients. PeerJ, 6, e5907. https://doi.org/10.7717/peerj.5907

10. Glass, J.M. (2009) Review of Cognitive Dysfunction in Fibromyalgia: A Convergence on Working Memory and Attentional Control Impairments. Rheumatic Disease Clinics of North America, 35, 299-311. https://doi.org/10.1016/j.rdc.2009.06.002

11. Tesio, V., Torta, D.M., Colonna, F., Leombruni, P., Ghiggia, A., Fusaro, E., Geminiani, G.C, Torta, R. and Castelli, L. (2015) Are Fibromyalgia Patients Cognitively Impaired? Objective and Subjective Neuropsychological Evidence. Arthritis Care \& Research (Hoboken), 67, 143-150. https://doi.org/10.1002/acr.22403

12. Carta, M.G., Moro, M.F., Pinna, F.L., Testa, G., Cacace, E., Ruggiero, V., Piras, M., Romano, F., Minerba, L., Machado, S. et al. (2018) The Impact of Fibromyalgia Syndrome and the Role of Comorbidity with Mood and Post-Traumatic Stress Disorder in Worsening the Quality of Life. International Journal of Social Psychiatry, 64, 647-655. https://doi.org/10.1177/0020764018795211 